\title{
Italian and Argentine olive oils: a NMR and gas chromatographic study
}

\author{
By Luisa Mannina ${ }^{1^{*}}$, Giuseppe Fontanazza ${ }^{2}$, Maurizio Patumi ${ }^{2}$, Giuliana Ansanelli ${ }^{3}$ and \\ Annalaura Segre ${ }^{4}$
}

\author{
${ }^{1}$ Università degli Studi del Molise, Facoltà di Scienze MM.FF.NN., 86170 Isernia, Italy and \\ Ist. Chimica Nucleare, CNR, CP 10, 00016 Monterotondo Staz., Roma Italy. \\ ${ }^{2}$ Ist. di Ricerche sull'Olivicoltura, CNR, Via della Madonna Alta 108, 06100 Perugia, Italy \\ ${ }^{3}$ C.R. ENEA-Trisaia, S. S. 106 Jonica, Km 419+500, 75025 Rotondella (MT), Italy \\ ${ }^{4}$ Ist. Chimica Nucleare, CNR, 00016 Monterotondo Staz., Roma, Italy
}

\section{RESUMEN}

Aceites de oliva de Italia y Argentina: Estudios de RMN y cromatografía gaseosa.

La espectroscopía de Resonancia Magnética Nuclear de alta resolución (RMN) y Cromatografía Gaseosa (CG) fueron utilizadas para analizar 16 monovariedades de aceites de oliva, obtenidas de algunos olivares Mediterráneos cultivados contemporáneamente en campos experimentales localizados en Italia y en la región de Catamarca en Argentina.

Estas muestras permiten estudiar diferentes condiciones pedoclimáticas en la composición de los aceite de oliva.

La CG proporciona el perfil en ácidos grasos de los aceites de oliva y las técnicas $\mathrm{RMN}{ }^{1} \mathrm{H}$ y $\mathrm{RMN}{ }^{13} \mathrm{C}$ suministran diferentes informaciones: el espectro $\mathrm{RMN}{ }^{1} \mathrm{H}$ permite medir los componentes menores del aceite de oliva tales como $\beta$-sitoesterol, hexanol, trans - 2 hexanol, formaldehido, escualeno, cicloartenol y ácido linolénico y el espectro $\mathrm{RMN}{ }^{13} \mathrm{C}$ da información referente a los triésteres de glicerol de los aceites de oliva, por ejemplo, la composición y distribución de la posición acílica en el glicerol.

Los datos de CG y RMN han sido sometidos a un análisis discriminante lineal (LDA) y a un análisis cluster en árbol (TCA).

Un minucioso análisis de estos resultados ha permitido seleccionar olivares que han sido menos afectados por las condiciones climáticas presentes en la región de Catamarca. Los olivares seleccionados producen aceites de oliva que pueden mantener sus características Mediterráneas y pueden ser propuestos como plantas colonizantes en esta región silvestre de Argentina.

PALABRAS-CLAVE: Aceite de oliva - Análisis estadístico Cromatografía gaseosa - NMR.

\section{SUMMARY}

Italian and Argentine olive oils: A NMR and gas chromatographic study.

High-field Nuclear Magnetic Resonance (NMR) spectroscopy and Gas Chromatography (GC) were used to analyze 16 monovarietal olive oils obtained from few matched Mediterranean cultivars grown in experimental fields located in Italy and in the Catamarca region of Argentina. The Catamarca region is characterized by extreme pedoclimatic conditions and by a wild spontaneous vegetation. The proposed sampling allows to study the effect of different pedoclimatic conditions on olive oil composition.

GC gives the fatty acid profile of olive oil samples. ${ }^{1} \mathrm{H}$ and ${ }^{13} \mathrm{C}$ NMR techniques provide different information: the ${ }^{1} \mathrm{H}$ NMR spectrum allows the measurement of minor components of olive oils such as $\beta$-sytosterol, hexanal, trans-2-hexenal, formaldehyde, squalene, cycloartenol and linolenic acid; the ${ }^{13} \mathrm{C}$ NMR spectrum allows to obtain information about glycerol tri-esters of olive oils, i.e., about their acyl composition and positional distribution on glycerol moiety. All the NMR and GC results have been submitted to Linear Discriminant Analysis (LDA) and Tree Cluster Analysis (TCA).

A careful analysis of the statistical results allows to select the Mediterranean cultivars less affected by the climatic conditions present in the Catamarca region. The selected cultivars produce olive oils which keep their Mediterranean characteristics and which can be proposed as colonizing plants in this wild Argentine region.

KEY-WORDS: Gas-chromatography - NMR - Olive oil - Statistical analysis.

\section{INTRODUCTION}

In recent years interest in extra virgin olive oils has grown; in fact, due to its recognized nutritional, sensory and healthy qualities, extra virgin olive oil is considered as a fundamental component of the Mediterranean diet. Moreover, the interest in olive oil, traditionally consumed in the Mediterranean area, has been extended to other countries such as Argentina, USA, Mexico, South Africa and Japan.

The official analytical definition of olive oil purity and quality, based on the European Community Regulation 2568/91 (EC, 1991), involves a panel test analysis and many different cumbersome analytical procedures.

It has been shown that high-resolution ${ }^{13} \mathrm{C}$ NMR spectroscopy is a technique able ton provide valuable information about the acyl composition and the sn (strictly numbered) 1,3 and sn 2 acyl positional distribution of glycerols tri-esters in different vegetable oils (Gunstone, 1990; Ng, 1985; Wollenberg, 1990; Mannina, 1999a; Mannina, 2000).

Our ${ }^{1} \mathrm{H}$ and ${ }^{13} \mathrm{C}$ NMR studies are relative to the characterization of edible oils. ${ }^{1} \mathrm{H}$ NMR spectroscopy, due to its higher sensitivity with respect to ${ }^{13} \mathrm{C}$ NMR, allows to analyze minor components (Segre, 1997), such as aldehydes and sterols, which are very useful for the determination of the geographical origin of 
Italian olive oils (Sacchi, 1998, Mannina, 2001a, Mannina, 2001b, Mannina,1999a).

${ }^{13} \mathrm{C}$ NMR technique provides (Mannina, 1999b, 2000) information about the fatty acid composition and the acyl distribution on the glycerol moiety; this information can be of crucial importance in the analytical characterization of edible oils and in the prevention of frauds such as the addition with esterified oils. This fatty chain distribution is usually assessed using a cumbersome and inaccurate enzymatic method (European Community Regulation) which cannot be applied to all vegetable oils (Balestrieri and Marini, 1991).

As the whole procedure seemed extremely useful and promising, the ${ }^{1} \mathrm{H}$ and ${ }^{13} \mathrm{C}$ NMR analyses were extended to olive oils coming from the same Mediterranean cultivars planted in Italy and in the Catamarca region of Argentina and to an olive oil coming from a typical Argentine cultivar.

Catamarca is an Argentine region characterized by a hot dry weather with temperatures reaching $45^{\circ} \mathrm{C}$ (Ravetti et al. 2000); moreover, near the vegetative re-growth, strong thermal variations between day and night are present. From a pedologic point of view, the soil of this region is mostly sandy-loam type, rich, deep and has a homogeneous profile. It has always had a spontaneous vegetation consisting mainly of bushes and shrubs. Lastly, it has been attempted to replace this vegetation by olive trees, which could then become the colonizing plants.

The purpose of this work is to select the Mediterranean cultivars able to produce a good quality product, even growing in the extreme climatic conditions present in the Catamarca region.

\section{EXPERIMENTAL}

\subsection{Samples}

The research has been carried out on 9 Argentine olive oils collected from the "Agropecuaria" farm, near Chañarito in the north-east of the Catamarca region, and on 8 Italian olive oils produced in various parts of Italy.

In Table I, the origin and the cultivar of these 17 olive oils, harvested in 1999, are reported (Fontanazza, 1987 and Ravetti, 2000); 16 olive oils come from 8 different Mediterranean cultivars (Biancolilla, Cerasuola, Coratina, 1-77, Frantoio, Kalamata, Leccino and Peranzana) grown in Italy and recently introduced in Argentina, and 1 olive oil comes from an Argentine cultivar (Arbequina) grown in the Catamarca region. Arbequina cultivar is considered to be identical to the homonymous variety which grows in Catalogna (Spain) and is widespread in Argentina, where it has been cultivated for many years.

"Biancolilla", "Cerasuola", "Coratina" and "Peranzana" are common cultivars from Southern Italy; "Frantoio" and "Leccino" are typical of central Italy; I-77 has an unknown origin and represents an IRO-CNR selection (Fontanazza, 1987); "Kalamata" is a typical "table" and "olive oil" cultivar from Greece: it is widespread in the Peloponnesian area and is well known in many countries (including South Africa) due to its high adaptability.

\subsection{Gas-chromatographic analysis}

Fatty acid transmethylation was carried out using methanolic potassium hydroxide which is a good derivatizing agent at both warm and room

Table I

Sample numbering, cultivar, origin and GC selected peak areas (\%) of Italian and Argentine olive oils harvested in 1999

\begin{tabular}{rcccccccccccc}
\hline Sample & Cultivar & Origin & c16:0 & C16:1 & c17:0 & c17:1 & c18:0 & C18:1 & C18:2 & C18:3 & c20:0 & c20:1 \\
\hline 1 & Arbequina & Argentina & 20.66 & 3.69 & 0.04 & 0.20 & 1.53 & 53.39 & 18.72 & 1.16 & 0.29 & 0.22 \\
2 & Biancolilla & Argentina & 16.31 & 1.81 & 0.11 & 0.19 & 1.80 & 70.47 & 7.34 & 1.12 & 0.37 & 0.31 \\
3 & Cerasuola & Argentina & 13.75 & 0.51 & 0.05 & 0.07 & 1.87 & 70.98 & 10.84 & 1.12 & 0.37 & 0.41 \\
4 & Coratina & Argentina & 16.29 & 0.67 & 0.05 & 0.08 & 1.77 & 71.50 & 7.99 & 1.27 & 0.37 & 0.35 \\
5 & I-77 & Argentina & 15.34 & 0.91 & 0.05 & 0.08 & 1.52 & 70.52 & 9.54 & 1.45 & 0.32 & 0.25 \\
6 & Frantoio & Argentina & 17.19 & 1.65 & 0.01 & 0.09 & 1.63 & 63.55 & 14.03 & 1.23 & 0.28 & 0.31 \\
7 & Kalamata & Argentina & 12.93 & 1.46 & 0.04 & 0.13 & 1.78 & 65.79 & 16.04 & 1.33 & 0.22 & 0.29 \\
8 & Leccino & Argentina & 17.39 & 1.16 & 0.05 & 0.09 & 1.71 & 68.45 & 9.19 & 1.43 & 0.33 & 0.25 \\
9 & Peranzana & Argentina & 18.16 & 1.79 & 0.02 & 0.07 & 2.21 & 62.57 & 13.08 & 1.37 & 0.36 & 0.32 \\
10 & Coratina & Italy & 12.36 & 0.51 & 0.08 & 0.05 & 2.1 & 75.43 & 7.94 & 0.72 & 0.31 & 0.33 \\
11 & Peranzana & Italy & 12.27 & 0.80 & 0.07 & 0.11 & 1.86 & 76.45 & 7.21 & 0.58 & 0.33 & 0.28 \\
12 & Frantoio & Italy & 12.34 & 1.01 & 0.01 & 0.02 & 1.65 & 75.77 & 8.04 & 0.55 & 0.29 & 0.29 \\
13 & Leccino & Italy & 13.23 & 1.25 & 0.01 & 0.09 & 1.53 & 77.96 & 4.54 & 0.68 & 0.28 & 0.33 \\
14 & I-77 & Italy & 9.82 & 0.50 & 0.05 & 0.12 & 1.58 & 80.54 & 5.82 & 0.70 & 0.32 & 0.39 \\
15 & Cerasuola & Italy & 9.86 & 0.22 & 0.02 & 0.03 & 2.54 & 76.83 & 9.34 & 0.51 & 0.36 & 0.34 \\
16 & Biancolilla & Italy & 11.61 & 0.52 & 0.12 & 0.20 & 2.23 & 74.10 & 9.81 & 0.69 & 0.39 & 0.31 \\
17 & Kalamata & Italy & 9.87 & 0.61 & 0.01 & 0.56 & 1.52 & 78.95 & 6.56 & 0.72 & 0.40 & 0.52 \\
\hline
\end{tabular}


temperature (European Community Regulation, 1977; Patumi, 1999; Odetokun S.M., 1998). The olive oil sample $(0.2 \mathrm{~g})$ was mixed with $0.2 \mathrm{~mL}$ of methanolic $\mathrm{KOH} 2 \mathrm{M}$ and $3 \mathrm{~mL}$ of hexane. After strong shaking $(1 \mathrm{~min})$, the hexane solution was analyzed to determine the methyl-ester content using a gas-chromatograph (Perkin Elmer Autosystem Gas Chromatograph, Norwalk, CT, U.S.A.) equipped with a flame ionization detector and a GP 3\% SP-2310 / 2\% SP-2300 on 100/120 Chrom W-HW column (6' x 1/8" stainless steel; Supelco, Bellefonte, PA, U.S.A.) operating at $200^{\circ} \mathrm{C}$, injector at $270^{\circ} \mathrm{C}$, detector at $250^{\circ} \mathrm{C}$.

\subsection{NMR spectra}

\section{${ }^{1} H N M R$}

The NMR technique, unlike traditional methods, allows analyzing olive oils without solvent extraction or chemical derivatization; the sample is analyzed as it is, without any possibility of decomposition or isomerization.

The ${ }^{1} \mathrm{H}$ NMR procedure reported by Segre and Mannina (1997) was followed. The olive oil samples for the NMR analysis were utilized without any extractions, derivatization or purification.

Olive oils $(20 \mu \mathrm{L})$ were placed into $5 \mathrm{~mm}$ NMR tubes and dissolved in chloroform-d $(700 \mu \mathrm{L})$ and DMSO-d $(20 \mu \mathrm{L})$. The addition of DMSO was necessary for the solubility of the polar minor components of the olive oil (Sacchi, 1996). The deuterium signal of $\mathrm{CDCl}_{3}$ was used to lock the magnetic field. ${ }^{1} \mathrm{H}$ NMR spectra were recorded at 300 $\mathrm{K}$ on a Bruker AMX 600 (Karlsruhe, Germany) instrument operating at $600.13 \mathrm{MHz}$. The deuterium signal of $\mathrm{CDCl}_{3}$ was used to lock the magnetic field.

${ }^{1} \mathrm{H}$ NMR FIDs were recorded using the following acquisition parameters: acquired points $32 \mathrm{~K}$, processed points $32 \mathrm{~K}$, spectral width $14 \mathrm{ppm}$, relaxation delay $2 \mathrm{~s}, \pi / 2$ pulse, acquisition time $1.5 \mathrm{~s}$, number of scans 4000 . The spectra were obtained by a simple Fourier transformation.

In order to achieve a quantitative evaluation of all peaks of interest, a careful baseline correction was performed. The intensities of the selected resonances were compared with that at $1.55 \mathrm{ppm}$ normalized to 1000; this procedure gives an index proportional to the molar ratio between each compound and the total amount of fatty chains.

The selected ${ }^{1} \mathrm{H}$ resonances used for determining the geographical origin (Sacchi, 1998 and Mannina $2001 \mathrm{a}, \mathrm{b})$ are: $\beta$-sytosterol (0.62 ppm), squalene (1.62 ppm), four resonances due to terpenes (in the spectral range of 4.45-5.00 ppm), formaldehyde (8.00 ppm), trans-2-hexenal $(9.45 \mathrm{ppm})$, hexanal $(9.70 \mathrm{ppm})$ and two other unsaturated aldehydes (9.53 ppm and $9.61 \mathrm{ppm}$ ).
To carry out the statistical analysis of ${ }^{1} \mathrm{H}$ NMR data, the normalized intensities of the selected resonances, chosen according to the following criteria have been used. First of all, the selected variables must be independent, that is, they cannot belong to the same molecule or to two molecules which are always in the same relative amount in olive oil.

Moreover, they must show sufficient variability in many samples (Sacchi, 1996) and must not be originated from defects of storage or preparation and, eventually, they must be in a spectral region not too crowed, so they can be analyzed easily.

The selected ${ }^{1} \mathrm{H}$ resonances, relative to the minor components of olive oils, have been submitted to the Tree Cluster Analysis (TCA) and to the Linear Discriminant Analysis (LDA).

\section{${ }^{13}$ C NMR}

Olive oil samples $(100 \mu \mathrm{L})$ were placed in 5 $\mathrm{mm}$ NMR tubes and dissolved in chloroform- $d$ $(600 \mu \mathrm{L})$.

${ }^{13} \mathrm{C}$ spectra were recorded at $300 \mathrm{~K}$ on a Bruker AMX600 spectrometer operating at $150.9 \mathrm{MHz}$ using the following acquisition parameters: acquired points $256 \mathrm{~K}$, processed points $128 \mathrm{~K}$, spectral width 195 ppm, digital resolution $0.22 \mathrm{~Hz}$ per point, relaxation delay 8 s. The GARP sequence (Shaka, 1985) was applied during the whole sequence for proton decoupling.

In order to perform the statistical analysis, the intensities of the following carbonyl signals have been measured: sn 1,3 (173.271 ppm) palmitic and stearic chains; sn 1,3 (173.261 ppm) eicosenoic and cis-vaccenic chains; sn 1,3 (173.241 ppm) and sn 2 (172.833 ppm) oleic chains; sn 1,3 (173.230 ppm) and sn 2 (172.821 ppm) linoleic chains. These intensities have been normalized dividing each of them by their total sum, as reported in Table II; then, these normalized data have been submitted to the TCA and to LDA.

\subsection{Statistical Analysis}

NMR and GC data were analyzed using Statistica software package for Windows ('97 Edition by Statsoft, Inc.). In particular, two statistical methods have been used: Tree Cluster Analysis (TCA) (Romesburg, 1984) and Linear Discriminant Analysis (LDA) (Morrison, 1990).

The TCA clusters the data into meaningful groups without any a priori hypothesis. This statistical analysis allows to see the natural grouping and gives information which can be used as a priori hypothesis for further analysis as LDA.

The TCA method joins together objects (olive oils) into successively larger clusters, using some measures of distance. All possible classification in a 
Table II

Sample numbering, cultivar, origin and normalized intensities of the methyl signal of linolenic acid in the ${ }^{1} \mathrm{H}$ spectra and of the carbonyl signals in the ${ }^{13} \mathrm{C}$ spectra of Italian and Argentine olive oils.

\begin{tabular}{|c|c|c|c|c|c|c|c|c|}
\hline Sample & Cultivar and origin & $\begin{array}{l}\text { Saturated } \\
\text { chains }\end{array}$ & $\begin{array}{c}\text { Eicosenoic } \\
\text { and cis- } \\
\text { vaccenic chain }\end{array}$ & $\begin{array}{l}\text { Oleic chain } \\
\text { sn } 1,3\end{array}$ & $\begin{array}{l}\text { Linoleic chain } \\
\quad \text { sn } 1,3\end{array}$ & $\begin{array}{l}\text { Oleic chain } \\
\text { sn } 2\end{array}$ & $\begin{array}{l}\text { Linoleic chain } \\
\quad \text { sn } 2\end{array}$ & $\begin{array}{l}\text { Linolenic } \\
\text { acid }\end{array}$ \\
\hline 1 & Arbequina-Argentina & 0.268 & 0.057 & 0.310 & 0.096 & 0.191 & 0.078 & 0.905 \\
\hline 2 & Biancolilla-Argentina & 0.213 & 0.044 & 0.400 & 0.046 & 0.267 & 0.029 & 1.052 \\
\hline 3 & Cerasuola-Argentina & 0.187 & 0.017 & 0.461 & 0.062 & 0.235 & 0.038 & 1.023 \\
\hline 4 & Coratina-Argentina & 0.226 & 0.022 & 0.438 & 0.045 & 0.242 & 0.028 & 1.179 \\
\hline 5 & I-77 Argentina & 0.223 & 0.037 & 0.412 & 0.053 & 0.246 & 0.029 & 1.153 \\
\hline 6 & Frantoio-Argentina & 0.235 & 0.045 & 0.367 & 0.096 & 0.216 & 0.040 & 1.153 \\
\hline 7 & Kalamata-Argentina & 0.166 & 0.028 & 0.394 & 0.084 & 0.259 & 0.068 & 1.190 \\
\hline 8 & Leccino-Argentina & 0.234 & 0.038 & 0.405 & 0.048 & 0.239 & 0.040 & 1.344 \\
\hline 9 & Peranzana-Argentina & 0.236 & 0.037 & 0.365 & 0.086 & 0.225 & 0.052 & 1.066 \\
\hline 10 & Coratina-Italy & 0.148 & 0.013 & 0.516 & 0.040 & 0.245 & 0.037 & 0.726 \\
\hline 11 & Peranzana-Italy & 0.174 & 0.022 & 0.458 & 0.040 & 0.268 & 0.038 & 0.686 \\
\hline 12 & Frantoio-Italy & 0.164 & 0.031 & 0.493 & 0.025 & 0.255 & 0.032 & 0.483 \\
\hline 13 & Leccino-Italy & 0.160 & 0.028 & 0.472 & 0.034 & 0.285 & 0.021 & 0.527 \\
\hline 14 & I-77-Italy & 0.125 & 0.018 & 0.523 & 0.026 & 0.279 & 0.029 & 0.604 \\
\hline 15 & Cerasuola-Italy & 0.145 & 0.017 & 0.481 & 0.073 & 0.233 & 0.051 & 0.700 \\
\hline 16 & Biancolilla-Italy & 0.183 & 0.012 & 0.448 & 0.053 & 0.251 & 0.053 & 0.640 \\
\hline 17 & Kalamata-Italy & 0.119 & 0.028 & 0.504 & 0.049 & 0.258 & 0.042 & 0.578 \\
\hline
\end{tabular}

prescribed number of groups can be obtained by cutting the tree at a suitable level. Different distance measures can be used to form clusters. In our study, the Euclidean distance, i.e. the geometric distance in the multidimensional space, has been used.

In the TCA, a linkage or amalgamation rule is necessary to determine when two clusters are sufficiently similar to be linked together. There are different linkage rules such as single linkage, complete linkage and un-weighted pair-group average. The un-weighted pair-group average linkage rule, for which the distance is calculated as the average distance between all pairs of objects in the two different clusters, has been chosen. This method is very efficient when objects form naturally distinct clumps.

The LDA is a multivariate statistical method used to determine which variables discriminate between two or more a priori defined groups. In our case, the a priori groups suggested by the TCA are Italy and Argentina. The selected variables are used to build up a data matrix and to give rise to a discriminant (canonical) linear equation. The scores, relative to each olive oil, derived from LDA are plotted relatively to the normalized intensities of the variable with the major discriminant power. The discriminant power of each variable has been evaluated by measuring the value of the Wilk's Lambda factor (Huberty, 1994) for the overall model after removing the selected variable. The Wilk's Lambda factor ranges from 0.0 (perfect discriminatory power) to 1.0 (no discriminatory power).

\section{RESULTS}

\subsection{Gas Chromatographic Analysis}

The gas chromatographic analysis gives the fatty acid composition of each analyzed olive oil, see Table I. This table includes the sample numbering, the cultivars, the origin and the GC peak areas of 10 selected fatty acids.

LDA analysis, applied to the 5 variables with the highest discriminating power (C16:1, C17:1, C18:3, C20:0 and C20:1) gives an adequate separation between Italian and Argentine olive oils (see Fig. 1A). This result proves that fatty acid composition is affected by the different pedoclimatic conditions present in Italy and in Catamarca. Note that, even employing only the two fatty acids with the highest discriminating power, i.e. palmitoleic and linolenic, LDA still provides a good separation (see Fig.1D).

The TCA applied to the same data set gives essentially the same results as shown in the dendrogram reported in Fig.2. This statistical analysis allows to obtain all the possible classifications in a prescribed number of groups. If the dendrogram is cut at the highest level ( $1^{\text {st }}$ level of Fig. 2), two groups are obtained: a group consisting of the olive oil from Arbequina cultivar, the other one consisting of all the other olive oils. Thus, Arbequina olive oil is completely different from all the others. This could be expected from its very different fatty acid profile (see Table I). Cutting the dendrogram at a 
A

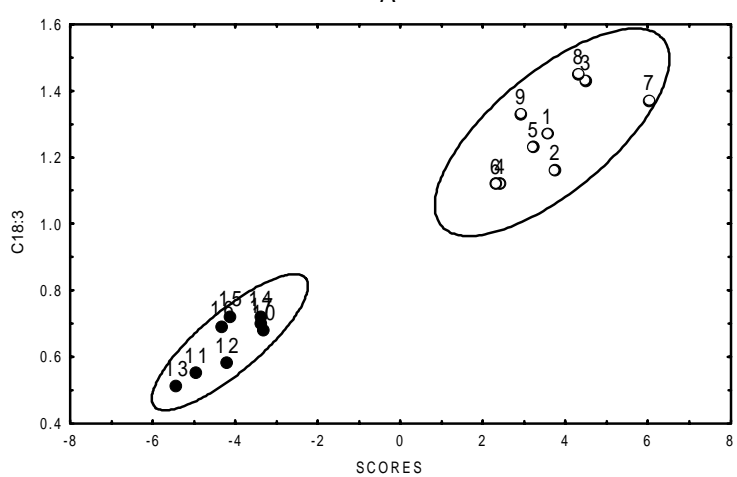

C

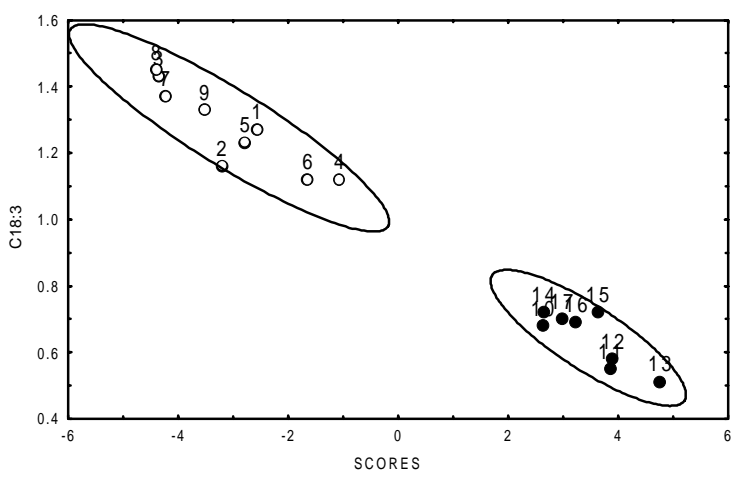

B

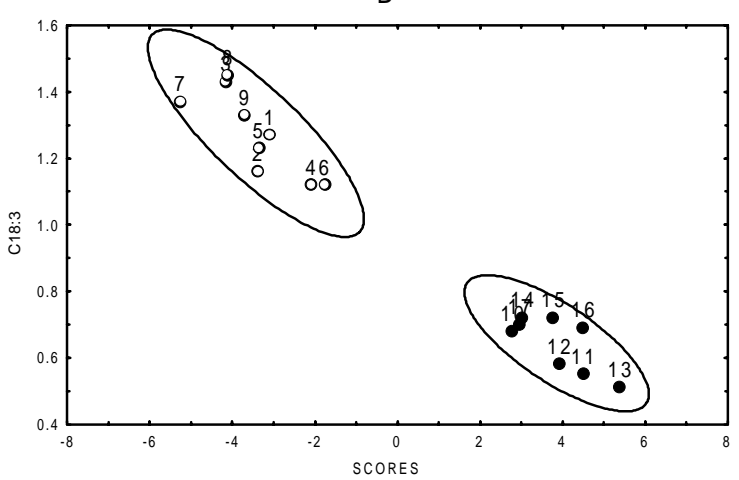

D

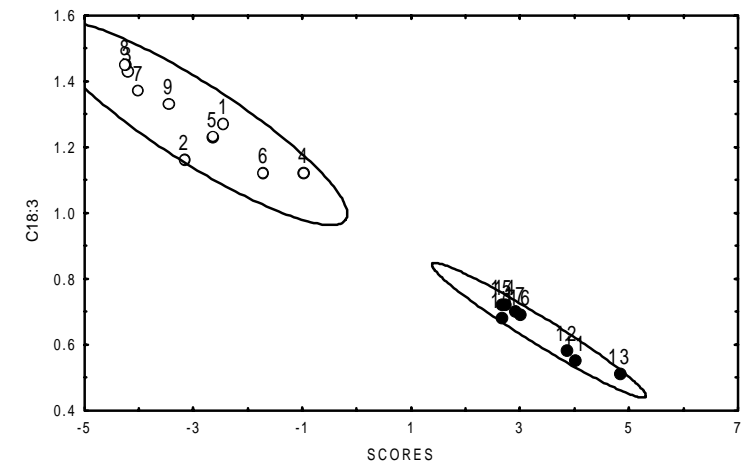

Figure 1

Linear Discriminant Analysis of Italian (•) and Argentine (o) olive oils performed on: A=5 GC (C16:1, C17:1, C18:3, C20:0, C20:1) selected peaks; $B=4$ GC $(C 16: 1, C 17: 1, C 18: 3, C 20: 1)$ selected peaks; $C=3$ GC $(C 16: 1, C 17: 1, C 18: 3)$ selected peaks; $D=2$ GC (C16:1, C18:3) selected peaks. The numbering identifies olive oil samples as reported in Table I. Ellipses represent the $95 \%$ co nfidence regions for each group.

lower level $\left(2^{\text {nd }}\right.$ level of Fig. 2) three groups are obtained: the first group consists of all the Italian olive oils and 4 Argentine olive oils (Leccino, I-77, Coratina and Cerasuola): these 4 cultivars, grown in

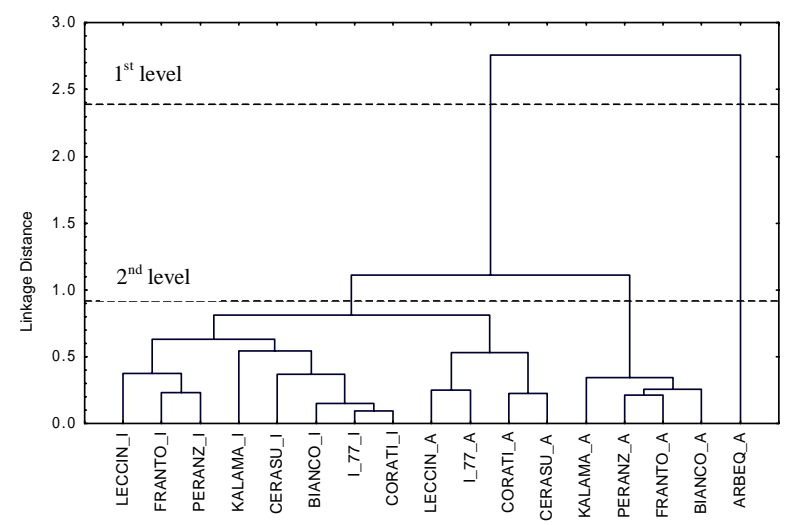

Figure 2

Dendrogram (TCA) showing the clustering, based on GC data (C16:1, C17:1, C18:3, C20, C20:1), of Italian (I) and Argentine (A) olive oils. Two levels corresponding to a different number of groups are marked.
Argentina, are able to produce olive oils similar to the Italian ones; the second group consists of 4 Argentine olive oils from Kalamata, Peranzana, Frantoio and Biancolilla; these 4 cultivars, therefore, in not Mediterranean climatic conditions, give a product with characteristics different with respect to the Italian one; the last group consists of the olive oil from Arbequina.

\subsection{NMR analysis}

In Fig. 3 the methyl (Fig. 3a) and carbonyl (Fig. 3b) regions of the ${ }^{13} \mathrm{C}$ NMR spectra of an Italian (I) olive oil and an Argentine (A) olive oil coming from the same cultivar (Frantoio) are reported.

The measurement of the intensity of the peaks in the methyl spectral region (data not reported) shows that the fatty acid composition of Argentine olive oils is rather different from that of the Italian ones. This observation agrees with the data obtained by GC analysis reported in Table I. In particular, Argentine olive oils present, with respect to Italian olive oils, a major amount of saturated fatty acids (palmitic and stearic) and of linoleic acid but a minor amount of oleic acid. 

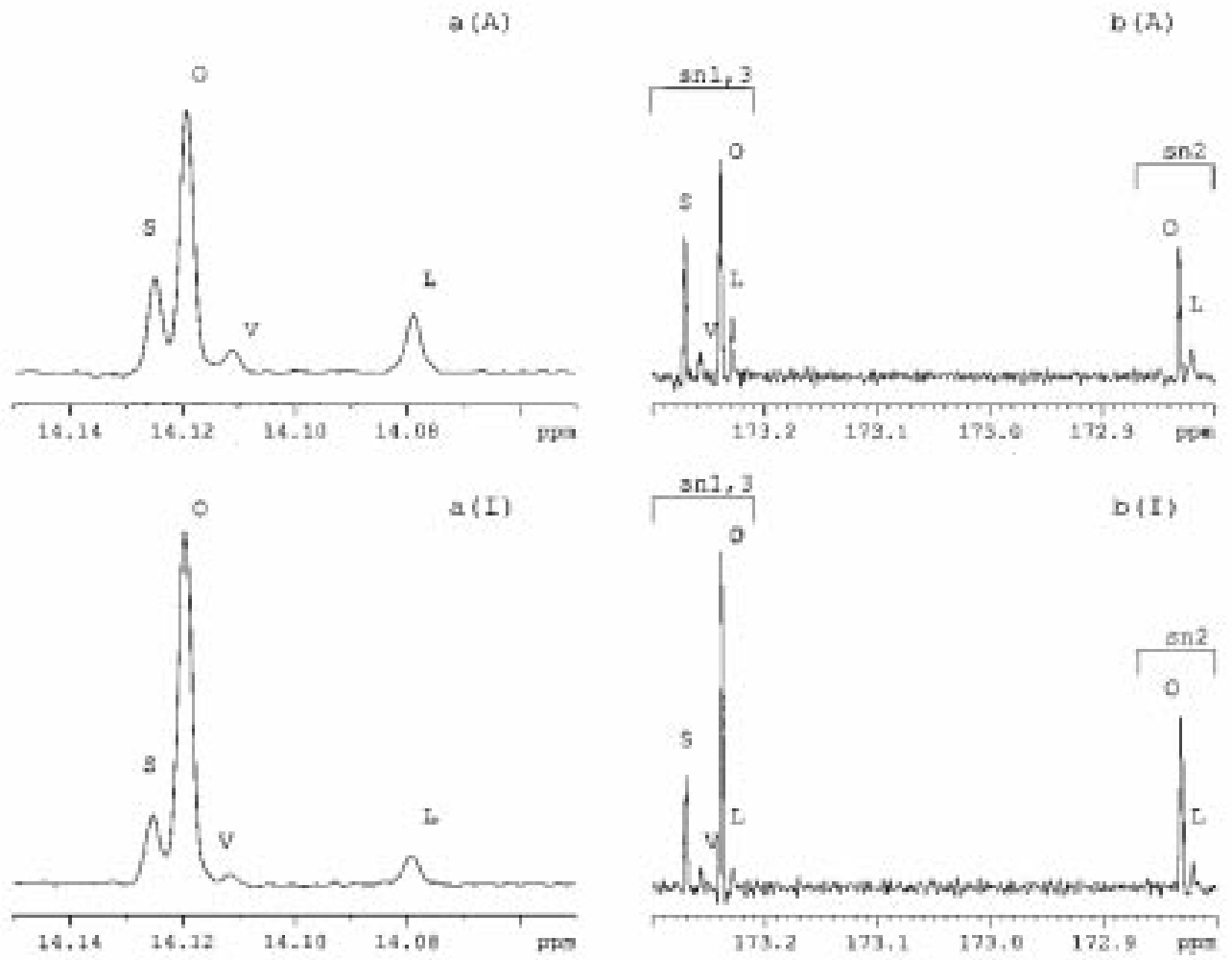

Figure 3

Methyl (a) and carbonyl (b) regions of ${ }^{13} \mathrm{C}$ spectra of an Italian (I) olive oil and an Argentine (A) olive oil. S=Saturated chains; $\mathrm{V}=\mathrm{Cis}-\mathrm{Vaccenic}$ and Eicosenoic chains; $\mathrm{O}=$ Oleic chain; $\mathrm{L}=\mathrm{Linoleic}$ chain.

The carbonyl region provides different information, that is, the knowledge of the sn 1,3 and sn 2 acyl distribution on the glycerol moiety (Mannina, 1999 and Mannina, 2000).

The LDA, applied to the six ${ }^{13} \mathrm{C}$ carbonyl resonances marked in Fig. $3 \mathrm{~b}$ (S, V, O, L, sn 1,3 and sn 2 ) and to the ${ }^{1} \mathrm{H}$ resonance due to linolenic acid, shows a good separation between Italian and Argentine olive oils (see Fig.4A). It must be observed that the Argentine olive oils from Cerasuola and Coratina cultivars (labeled 3 in Fig. 4) belongs clearly to the Argentine group but they lie quite far away from all the other Argentine olive oils. This result suggests that olive oils from these cultivars have a fatty acid composition different from the other ones. Similar results (see fig. 4B, 4C, 4D, 4E, 4F) are obtained reducing the number of variables down to the two fatty acids with the highest discriminant power (C18:3 and C18:1 (cis 11)), as reported below: fig. 4 B: C16:0+C18:0; C18:1 (cis 11); C18:1 (cis 9) sn1,3 and sn2; C18:2 sn1,3; C18:3. fig. 4 C: C16:0+C18:0; C18:1 (cis 11); C18:1 (cis 9) sn 2; C18:2 sn 1,3; C18:3.

fig. 4 D: C16:0+ C18:0; C18:1 (cis 11); C18:2 sn 1,3; C18:3.

fig. 4 E: C16:0+C18:0; C18:1 (cis 11); C18:3. fig. 4 F: C18:1 (cis 11); C18:3.
The TCA, applied to the same data set, gives the dendrogram reported in Fig. 5. Cutting the tree at the highest level $\left(1^{\text {st }}\right.$ level in Fig.5) two groups are obtained: a group consisting of the olive oil from Arbequina cultivar and the second one consisting of all the other olive oils. On this regard, GC and NMR give exactly the same information. Cutting the dendrogram at a lower level ( $2^{\text {nd }}$ level in Fig. 5) three groups are present: one containing only Arbequina olive oil, the second one containing Argentine olive oils and the last one containing all the Italian olive oils plus one Argentine olive oil from Cerasuola cultivar. This result shows that the Cerasuola cultivar grown in Catamarca produce an olive oil with the fatty acid composition similar to that of the Italian product.

In previous works ${ }^{1} \mathrm{H}$ NMR analysis has been used to characterize the geographical origin of Italian olive oils (Sacchi, 1998; Mannina, 2001a; Mannina 2001b): this method relies mostly on minor components. Among these minor components, the volatile aldehydes, terpenes responsible for the sensory quality of olive oils, so important in the Italian olive oil geographical characterization, are not very useful in discriminating Italian from Argentine olive oils; in fact, they do not show a sufficient variability (see Table III) between the Italian and 

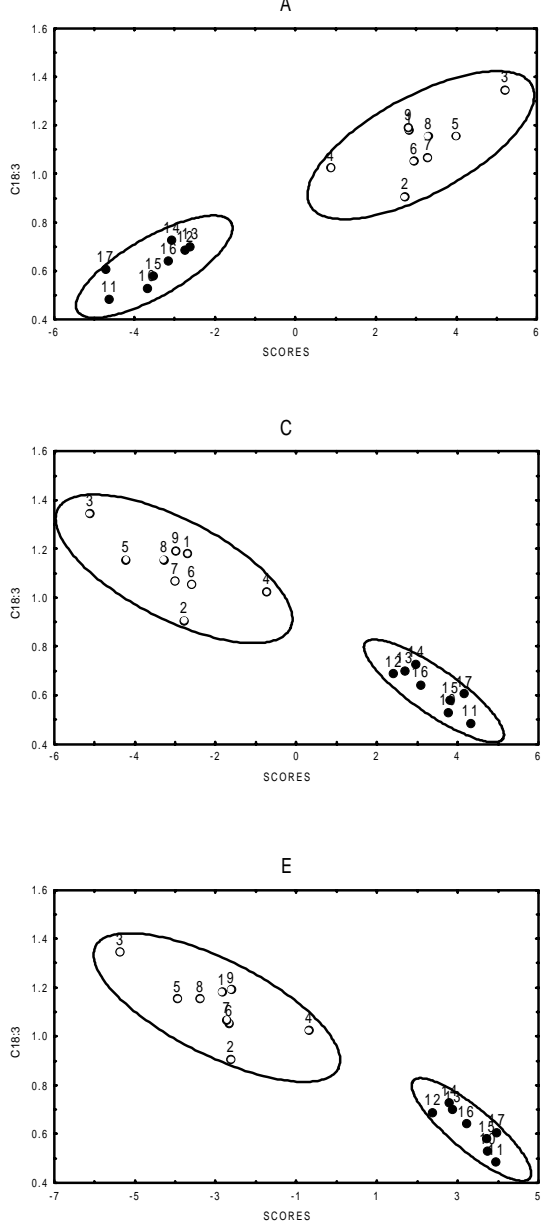

B
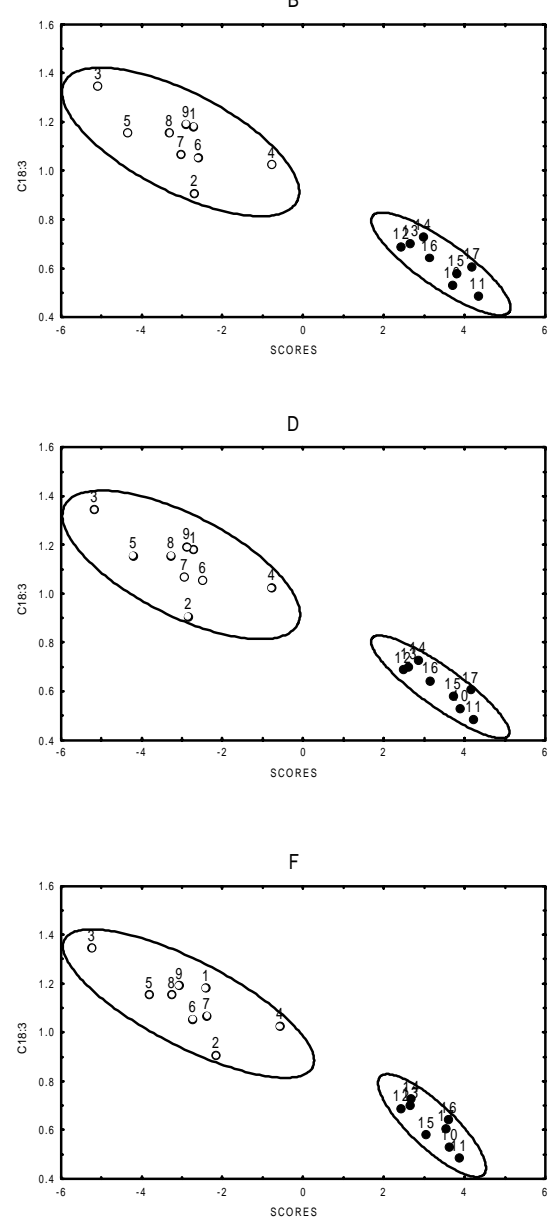

Figure 4

Linear Discriminant Analysis of Italian $(\bullet)$ and Argentine $(0)$ olive oils performed on: $A=C 18: 3\left({ }^{1} \mathrm{H}\right)+6{ }^{13} \mathrm{C}$ selected resonances; $\mathrm{B}=\mathrm{C} 18: 3\left({ }^{1} \mathrm{H}\right)+5{ }^{13} \mathrm{C}$ selected resonances; $\mathrm{C}=\mathrm{C} 18: 3\left({ }^{1} \mathrm{H}\right)+4{ }^{13} \mathrm{C}$ selected resonances; $\mathrm{D}=\mathrm{C} 18: 3\left({ }^{1} \mathrm{H}\right)+3{ }^{13} \mathrm{C}$ selected resonances; $E=C 18: 3\left({ }^{1} \mathrm{H}\right)+2{ }^{13} \mathrm{C}$ selected resonances; $F=C 18: 3\left({ }^{1} \mathrm{H}\right)+1{ }^{13} \mathrm{C}$ selected resonances. The numbering identifies olive oil samples as reported in Table I. Ellipses represent the $95 \%$ confidence regions for each group.

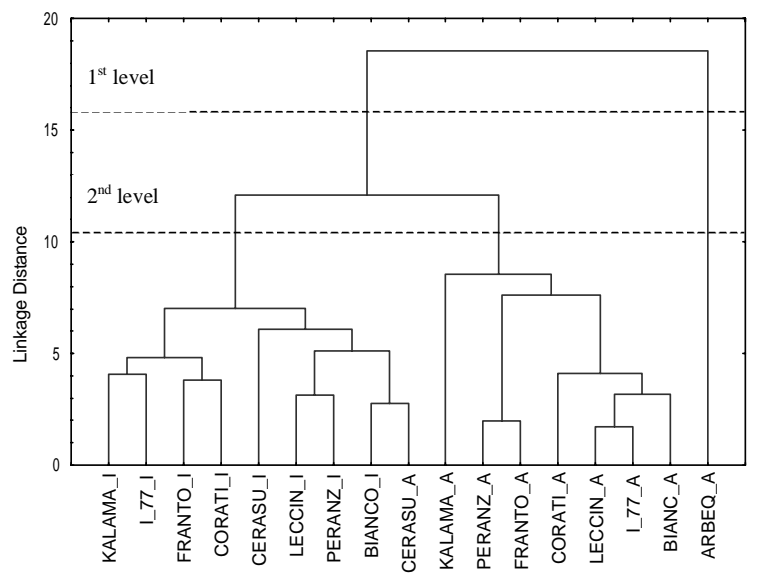

Figure 5

Dendrogram (TCA) showing the clustering, based on $\operatorname{six}{ }^{13} \mathrm{C}$ and one ${ }^{1} \mathrm{H}(\mathrm{C} 18: 3)$ selected resonances of Italian (I) and Argentine (A) olive oils. Two levels corresponding to a different number of groups are marked.
Argentine groups and do not allow a good clustering (data not shown). On the other hand, ${ }^{1} \mathrm{H}$ NMR spectra show that other minor components such as $\beta$-sytosterol and linolenic acid have a good variability; in fact Argentine olive oils are characterized by a major amount of -sytosterol and linolenic acid (>1\%) with respect to the Italian olive oils (see Table III).

\section{DISCUSSION}

GC and NMR techniques allow to obtain an adequate profile of olive oils composition.

The major components of olive oils are the triglycerides. Saturated fatty chain are not "good" constituents from a nutritional point of view since they increase the amount of cholesterol in human blood. Monounsaturated fatty acids instead, such as oleic acid, are "good" constituents because they contribute to limit cardiovascular risks by reducing the amount of cholesterol in blood. Finally, the 
Table III

Sample numbering, cultivar, origin and normalized intensities of the selected resonances in the ${ }^{1} \mathrm{H}$ spectra of Italian and Argentine olive oils.

\begin{tabular}{|c|c|c|c|c|c|c|c|c|c|c|c|c|c|}
\hline Sample & Cultivar & Origin & $\beta$-sytosterol & Squalene & $\begin{array}{l}\text { Terpenes } \\
\text { (4.52 ppm) }\end{array}$ & $\begin{array}{l}\text { Terpenes } \\
(4.60 \mathrm{ppm})\end{array}$ & $\begin{array}{l}\text { Terpenes } \\
\text { (4.66 ppm) }\end{array}$ & $\begin{array}{l}\text { Terpenes } \\
(4.89 \mathrm{ppm})\end{array}$ & Formaldehyde & $\begin{array}{l}\text { trans-2- } \\
\text { hexenal }\end{array}$ & $\begin{array}{c}\text { unsaturated } \\
\text { aldehyde } \\
(9.53 \mathrm{ppm})\end{array}$ & $\begin{array}{l}\text { unsaturated } \\
\text { aldehyde } \\
(9.61 \mathrm{ppm})\end{array}$ & hexanal \\
\hline 1 & Arbequina & Argentina & 13.099 & 11.952 & 2.937 & 0.623 & 0.730 & 0.783 & 1.496 & 5.844 & 0.364 & 0.230 & 5.131 \\
\hline 2 & Biancolilla & Argentina & 9.429 & 71.203 & 0.475 & 0.398 & 0.000 & 1.476 & 1.903 & 4.808 & 0.249 & 0.265 & 4.539 \\
\hline 3 & Cerasuola & Argentina & 12.774 & 40.241 & 0.481 & 0.530 & 0.410 & 1.332 & 2.340 & 4.860 & 0.386 & 0.384 & 4.971 \\
\hline 4 & Coratina & Argentina & 12.617 & 34.392 & 0.276 & 0.422 & 0.250 & 1.105 & 2.534 & 4.472 & 0.270 & 0.268 & 4.645 \\
\hline 5 & 177 & Argentina & 22.446 & 52.814 & 0.663 & 0.765 & 0.620 & 1.316 & 2.754 & 4.688 & 0.336 & 0.302 & 4.268 \\
\hline 6 & Frantoio & Argentina & 15.518 & 24.171 & 1.187 & 1.045 & 0.990 & 0.801 & 2.799 & 5.464 & 0.464 & 0.391 & 4.935 \\
\hline 7 & Kalamata & Argentina & 18.415 & 20.544 & 0.763 & 1.622 & 1.500 & 0.699 & 2.931 & 6.100 & 0.730 & 0.350 & 5.066 \\
\hline 8 & Leccino & Argentina & 18.412 & 41.343 & 1.375 & 0.872 & 0.790 & 1.184 & 2.621 & 4.446 & 0.332 & 0.232 & 4.263 \\
\hline 9 & Peranzana & Argentina & 15.682 & 23.526 & 1.319 & 1.162 & 1.100 & 0.914 & 2.977 & 5.510 & 0.496 & 0.386 & 5.223 \\
\hline 10 & Coratina & Italy & 8.671 & 22.915 & 0.352 & 0.632 & 0.480 & 1.122 & 2.165 & 4.612 & 0.265 & 0.263 & 5.277 \\
\hline 11 & Peranzana & Italy & 9.046 & 37.009 & 0.643 & 1.066 & 0.828 & 1.040 & 3.536 & 5.094 & 0.539 & 0.286 & 5.032 \\
\hline 12 & Frantoio & Italy & 8.915 & 22.816 & 0.762 & 1.066 & 0.860 & 1.115 & 2.405 & 4.818 & 0.315 & 0.293 & 5.247 \\
\hline 13 & Leccino & Italy & 8.836 & 25.828 & 0.699 & 0.850 & 0.810 & 1.028 & 3.121 & 5.104 & 0.214 & 0.322 & 5.471 \\
\hline 14 & 177 & Italy & 9.156 & 38.752 & 0.471 & 0.793 & 0.600 & 1.269 & 3.128 & 4.956 & 0.249 & 0.239 & 5.436 \\
\hline 15 & Cerasuola & Italy & 9.902 & 25.647 & 0.440 & 1.273 & 1.100 & 1.077 & 4.137 & 5.414 & 0.554 & 0.375 & 5.054 \\
\hline 16 & Biancolilla & Italy & 9.485 & 31.312 & 0.507 & 0.944 & 0.820 & 1.183 & 4.487 & 5.370 & 0.493 & 0.628 & 5.690 \\
\hline 17 & Kalamata & Italy & 11.137 & 16.940 & 0.487 & 1.570 & 1.500 & 0.829 & 2.603 & 4.854 & 0.386 & 0.334 & 5.407 \\
\hline
\end{tabular}

polyunsaturated can turn the olive oil rancid reacting with oxygen and producing free radicals and peroxides.

NMR and GC results show that olive oils from Mediterranean cultivars grown in Italy and in Catamarca have a different fatty acid composition with respect to the olive oil from Arbequina cultivar grown in the same Argentine region. The olive oil from Arbequina is of poor quality since it has an extremely high content of polyunsaturated, linoleic and linolenic fatty acids but a low amount of oleic acid. Thus, the Arbequina cultivar widespread in South America cannot be proposed as a colonizing plant in the Catamarca region.

As far as the Mediterranean cultivars are concerned, it has been shown that there is a clear pedoclimatic effect on the fatty acid composition; in fact, the statistical analysis yields a adequate discrimination between Italian and Argentine olive oils. In particular, the extreme pedoclimatic conditions present in Catamarca result in a lower amount of oleic acid and in a higher amount of saturated and polyunsaturated (linolenic and linoleic) fatty chains. As a matter of fact, the concentration of linolenic acid in Argentine olive oils is over the limit (1\%) set by EEC regulation 2568/91 for extra virgin olive oils.

Moreover, ${ }^{1} \mathrm{H}$ NMR data show that Argentine olive oils are characterized by a major amount of $\beta$-sytosterol acid $(>1 \%)$ with respect to the Italian olive oils. It is important to underline that some components such as linolenic acid and $\beta$-sytosterol which do not show generally a good variability among Italian olive oils coming from different geographical areas, are of some utility for the discrimination between Italian and Argentine olive oils; in fact, these components exhibit a good variability when the olive oil trees are submitted to extremely different pedoclimatic conditions. On the other hand, other minor volatile compounds responsible for the sensory attributes do not show a adequate variability; thus, the amount of these compounds does not depend on the pedoclimatic factor.

The statistical analyses applied to GC and NMR data allow to check the Mediterranean cultivars less affected by the pedoclimatic condition present in Catamarca and able to produce olive oils similar to the Italian ones. The selected cultivars are Coratina and especially Cerasuola; in fact, the LDA analysis shows that olive oils from these two cultivars are always lie quite far away from the center of the ellipses and so from all the other Argentine olive oils. Moreover, TCA analysis performed on GD and NMR data shows that these olive oils are grouped together with the Italian ones.

Thus, these two cultivars of South Italy could be propose as colonizing plants suitable to produce good quality olive oils in extreme pedoclimatic conditions.

Lie quite far away from all the other Argentine olive oils.

\section{ACKNOWLEDGMENTS}

This work has been partly financed with a contribution of EEC in the "Promotion of Oliviculture" program "Ricerca Sviluppo Tecnologico e Alta Formazione”. 
G.A. work has been supported by Project SIA, partly founded by EU Structural Funds.

\section{BIBLIOGRAPHY}

Balestrieri, F., Marini, D. (1991). Metodi di Analisi Chimica dei prodotti Alimentari, 1st ed. Monolite, Rome.

European Community Regulation 2568/91. (1991). Off. J. European Community, L 248.

European Economic Community. (1977). European Community regulation no. 72/77.

Fontanazza, G. (1987). Presentiamo la cultivar I-77. Terra e Vita. 48,10-11.

Gunstone, F.D. (1990). ${ }^{13} \mathrm{C}-\mathrm{NMR}$ spectra of some synthetic glycerol esters alone and as mixtures. Chem. Phys. Lipids, 56, 195-199.

Huberty, C. J. (1994). Applied Discriminant Analysis. A Wiley Interscience Publication, John Wiley \& Sons, Inc. New York. USA

Mannina, L., Barone, P., Patumi, M., Fiordiponti, P., Emanuele, M.C. y Segre, A.L. (1999a). Cultivar and pedoclimatic effect in the discrimination of olive oils: a high-field NMR study. Recent Res. Devel. in Oil Chem. 3, 85-92.

Mannina, L., Luchinat, C., Emanuele, M. C. y Segre, A.L. (1999b). Acyl positional distribution of glycerol tri-esters in vegetable oils: a ${ }^{13} \mathrm{C}$ NMR study. Chem. Phys. Lipids, 103, 47-55.

Mannina, L., Luchinat, C., Patumi, M., Emanuele, M. C., Rossi, E. y Segre, A.L. (2000). Concentration dependence of ${ }^{13} \mathrm{C}$ NMR spectra of triglycerides: implications for the NMR analysis of olive oils. Magn. Reson. Chem. 38, 886-890.

Mannina, L., Patumi, M., Proietti, N., Bassi, D. y Segre, A.L. (2001a). Geographical Characterization of Italian extra virgin olive oils using high-field ${ }^{1} \mathrm{H}$ NMR spectroscopy. $J$. Agric. Food Chem., in press.

Mannina, L., Patumi, M., Proietti, N. y Segre, A.L. (2001b). Geographical Characterization of extra virgin olive oils of Tuscany using high-field 'H NMR spectroscopy. Ital. J. of Food Sci. 13, 55-66.
Morrison, D.F. (1990). Multivariate statistical methods. McGraw-Hill, Inc., USA, third ed., 269.

$\mathrm{Ng}, \mathrm{S}$. (1985). Analysis of positional distribution of fatty acids in palm oil by ${ }^{13} \mathrm{C}$ NMR spectroscopy. Lipids, 20, 778-782.

Odetokun, S.M. (1998). Chemical characteristics and effect of storage on the fatty acid of Manihot Glaziovii seed oil. Riv . Ital. Sostanze Grasse, LXXV, 301- 303.

Patumi, M., D’Adria, R., Fontanazza, G., Morelli, G., Giorio, P. y Sorrentino, G. (1999). Yield and oil qualità of intensively trained trees of three cultivars of olive (Olea europea L.) under different irrigation regimes. $J$. of Hort. Sci. \& Biothech. 74, 729-737.

Ravetti, L., Matias, C., Fontanazza, G., Patumi, M. y Rocchi, P. (2000). First observations regarding oil accunulation and other phenological aspects within the new olive production zone of Catamarca, Argentina. $4^{\text {th }}$ International Symposium on Olive Growing "Olive 2000", 25-30 Settembre Valenzano (Bari) Italy.

Sacchi, R., Patumi, M., Fontanazza, G., Fiordiponti, P., Mannina, L., Rossi, E. y Segre, A.L. (1996). A high-field ${ }^{1} \mathrm{H}$ Nuclear Magnetic Resonance study of the minor components in virgin olive oils. J. Am. Oil Chem. Soc. 23, 747- 758.

Sacchi, R., Mannina, L., Fiordiponti, P., Barone, P., Paolillo, L., Patumi, M. y Segre, A.L. (1998). Characterization of Italian extra virgin olive oils using $\mathrm{H}$ NMR Spectroscopy. J. Agric . Food Chem. 46, 3947-3951.

Segre, A.L. y Mannina, L. (1997). 'H NMR study of edible oils, Recent Res. Devel. in Oil Chem. 1, 297- 308.

Shaka, J., Barker, S.B. y Freeman, R.J. (1985). Computer-optimized decoupling scheme for wideband applications and low-level operation. J. Magn. Reson. 64, 547-552.

Wollenberg, K.F. (1990). Quantitative high resolution 13C nuclear magnetic resonance of the olefinic and carbonyl carbons of edible vegetable oils. J. Am. Oil Chem. Soc. 67, 487-494. 